\title{
Antioxidant Effect of Nanoemulsions Containing Extract of Achyrocline satureioides (Lam) D.C.-Asteraceae
}

\author{
Giovanni Konat Zorzi, ${ }^{1}$ Fernanda Caregnato, ${ }^{2}$ José Cláudio Fonseca Moreira, ${ }^{2}$ \\ Helder Ferreira Teixeira, ${ }^{1}$ and Edison Luis Santana Carvalho ${ }^{3,4}$
}

Received 5 March 2015; accepted 28 August 2015; published online 11 September 2015

\begin{abstract}
Ethanolic extracts of Achyrocline satureioides have pronounced antioxidant activity mainly due to the presence of the flavonoid quercetin. However, direct topical application of the extract is not possible due to the presence of high amounts of ethanol. In this sense, nanoemulsions arise as an alternative for topical formulation associating molecules with limited aqueous solubility. This article describes the development of topical nanoemulsions containing either $A$. satureioides extract or one of its most abundant flavonoid, quercetin. Nanoemulsions composed of octyldodecanol, egg lecithin, water and extract (NEE), or quercetin (NEQ) were prepared by spontaneous emulsification. This process led to monodisperse nanoemulsions presenting a mean droplet size of approximately 200-300 nm, negative zeta potential, and high association efficiency. A study of quercetin skin retention using porcine skin which was performed using a Franz diffusion cell revealed a higher accumulation of quercetin in skin for NEE when compared to NEQ. Finally, the antioxidant activity of formulations was measured by thiobarbituric acidreactive species and the APPH model. A lower lipoperoxidation for the extract in respect to quercetin solution was observed. However, no difference between NEQ and NEE lipoperoxidation could be seen. The protection against lipoperoxidation by the formulations was also measured in the skin, where lower formation of reactive species was observed after treatment with NEE. In conclusion, this study shows the formulation effect on the physicochemical properties of nanoemulsions as well as on the skin retention and antioxidant activity of quercetin.
\end{abstract}

KEY WORDS: Achyrocline satureioides; extractive solution; nanoemulsion; quercetin; topical antioxidant.

\section{INTRODUCTION}

The discovery that free radicals involved in the pathology of several diseases, such as cancer, diabetes, heart diseases, neurodegenerative dysfunctions, and specially in the aging process, led to increasing research of new sources of antioxidants $(1,2)$. Antioxidants are substances capable of neutralizing free radicals, thus preventing biological damage. When the balance between free radicals and antioxidant production is

Electronic supplementary material The online version of this article (doi:10.1208/s12249-015-0408-8) contains supplementary material, which is available to authorized users.

${ }^{1}$ Programa de Pós-graduação em Ciências Farmacêuticas, Universidade Federal do Rio Grande do Sul (UFRGS), Av. Ipiranga 2752, 90610-000, Porto Alegre, RS, Brazil.

${ }^{2}$ Programa de Pós-graduação em Bioquímica, Universidade Federal do Rio Grande do Sul (UFRGS), R. Ramiro Barcelos 2600, 90035003, Porto Alegre, RS, Brazil.

${ }^{3}$ Programa de Pós-graduação em Produtos Bioativos e Biociências, Universidade Federal do Rio de Janeiro, Av. Aluisio da Silva Gomes 50, 27930-560, Macaé, Brazil.

${ }^{4}$ To whom correspondence should be addressed. (e-mail: ffelsc@yahoo.com.br) disrupted, oxidative stress is achieved. In some cases, to prevent extensive cellular damage from oxidative stress, an antioxidant supplementation may be required $(3,4)$.

In recent years, the antioxidant activity of Achyrocline satureioides extracts has been extensively studied. This plant is native to South America and grows in Brazil, Argentina, Uruguay, and Paraguay, and many other activities have been attributed, including antiinflammatory, antiviral, and antimicrobial (5-7). The antioxidant potential of the methanolic and ethanolic extractive solutions of $A$. satureioides has already been described $(6,8)$. Interestingly, some fractions of lyophilized ethanolic extracts proved to be more effective than isolated compounds, leading to the conclusion that possible synergism occurs $(9,10)$. Regardless of the study, the antioxidant activity in $A$. satureioides extracts is attributed to the presence of phenolic compounds, specially the flavonoid quercetin. Quercetin has higher antioxidant activity, when compared to other flavonoids present in A. satureioides extracts. Three possible mechanisms of action have been related so far: oxygen derivate free radical scavenger, ion chelation, and inhibition of lipid peroxidation (11-13).

Topical administration of antioxidants has been extensively studied, mainly through means to reduce the effects of oxidative stress $(14,15)$. However, many compounds exhibit important hydrophobicity, making the formulation a chal- 
lenge. Quercetin displays an amphipathic behavior due to phenyl rings forming the hydrophobic part of the molecule and the hydroxyl groups constituting the polar portion (16). Nevertheless, intramolecular hydrogen bond leads to high partition coefficient, even though five free hydroxyl groups are present (17). For that, the proper selection of the vehicle for drug delivery is of utmost importance. Nanoemulsions have been considered to be a promissory delivery system for drugs with poor water solubility, and they have already been proposed for flavonoid association $(18,19)$. They present kinetic stability in comparison to classic emulsions and offer higher surface area, optimal for topical applications (20,21). A welldocumented literature has shown that the association of isolated bioactive compounds into nanotechnology-based delivery systems may present several advantages when compared to conventional dosage forms, including increase in the solubility, reduction of side effects, controlled released of the active compound, and increase in the drug stability (22-24).

So, the purpose of this study was to investigate the main physicochemical properties, the antioxidant activity, as well as the permeation profile of nanoemulsions containing A. satureioides extract in comparison to nanoemulsions containing only the isolated flavonoid (quercetin).

\section{MATERIALS AND METHODS}

\section{Materials}

Ethanol, sodium chloride, and sodium phosphate were obtained from Nuclear (Brazil). HPLC-grade methanol was purchased from Tedia (USA). Trifluoroacetic acid (TFA), 1,1,3,3-tetramethoxypropane (TMP), and 2,2'-Azobis(2methylpropionamidine) (AAPH) were purchased from Sigma (Brazil). For the preparation of nanoemulsions, Lipoid E-80 (egg lecithin) and octyldodecanol were obtained from Lipoid (Germany) and Delaware (Brazil), respectively. Porcine ears were obtained from a local slaughter house (Dhália, Brazil).

\section{Preparation and Characterization of A. satureioides Extracts}

A. satureioides extract was prepared as described elsewhere (9). Previously, all the inflorescence was separated and milled in a rotor mill (Pulverisette 14, Fritsch, Germany) with a 1-mm exit sieve. After that, maceration of $75 \mathrm{~g}$ of inflorescence in $1000 \mathrm{~mL}$ of an $80 \%$ ethanolic solution $(v / v)$ was performed through 8 days, at room temperature $\left(25^{\circ} \mathrm{C}\right)$, protected from the light, with one daily agitation. After this period, the extract was filtered, and the volume adjusted with $80 \%$ ethanol solution until the final volume of $1000 \mathrm{~mL}$.

The extract was characterized by means of dry residue, $\mathrm{pH}$, density, and amount of quercetin. The dry residue was determined by the residual weight of $20.0 \mathrm{~g}$ of extract, after evaporation until complete dryness (25). For that, the samples were placed in an oven at $105^{\circ} \mathrm{C}$ until constant weight. The density was determined using a $10-\mathrm{mL}$ pycnometer at $25^{\circ} \mathrm{C}$ and the result expressed in mean and standard deviation of three independent measurements. Determination of $\mathrm{pH}$ was performed using $10 \mathrm{~mL}$ of extractive solution in a potentiometer ( $\mathrm{pH}$ meter B374, Micronal, Brazil), previously calibrated with solution at $\mathrm{pH} 4.0$ and 7.0. The results were expressed in mean and average of three different analyses, both as indicated in an official compendium (US Pharmacopeia) (26). The quantification of quercetin was carried out by HPLC-UV, revalidating the methodology described by De Souza et al. (9). The HPLC apparatus consisted of a LC10AD liquid chromatograph and CBM-10A communication bus module, using an SPD-10A UV-VIS detector (all from Shimadzu, Japan). A Shim-pack CLC-ODS (M) RP-18 $(5 \mu \mathrm{m}, 250 \times 4 \mathrm{~mm}$ i.d.) column was used with a flow rate of $0.6 \mathrm{~mL} / \mathrm{min}$ and UV detection at $362 \mathrm{~nm}$. The mobile phase consisted of a mixture of methanol/water (53:47) with TFA $0.1 \%$ (final concentration). The summary of properties of the extractive solution can be seen in Table I. The method was also validated for the quantification of quercetin in the nanoemulsion and in the porcine skin (see Supplementary Information).

\section{Nanoemulsion Preparation and Characterization}

\section{Preparation of Nanoemulsions by Spontaneous Emulsification}

Nanoemulsions were prepared using spontaneous emulsification by solvent displacement, as previously described (27). For that, $30 \mathrm{~mL}$ of ethanolic solution containing egg lecithin (200 mg), octyldodecanol ( $800 \mathrm{mg}$ ), and A. satureioides extract (or quercetin solution) was poured in $60 \mathrm{~mL}$ of water under magnetic stirring. After $10 \mathrm{~min}$, the ethanol was removed under reduced pressure in a rotatory evaporator until a final volume of $10 \mathrm{~mL}$. Nanoemulsions containing quercetin (NEQ) or extract (NEE) with a total amount of $100 \mu \mathrm{g}$ of quercetin were prepared as well as a blank nanoemulsion (NEB). The resulting formulations with $10 \%$ of the internal phase were then characterized.

\section{Determination of Mean Average Size}

The mean droplet size and the size distribution were determined by dynamic light scattering. For that, the samples were diluted within the appropriate concentration with $1 \mathrm{mM}$ $\mathrm{NaCl}$. Each analysis was carried out at $25^{\circ} \mathrm{C}$ with a detection angle of $173^{\circ}$ using a Zetasizer Nano ZS (Malvern, UK).

\section{Determination of Zeta Potential}

Zeta potential was obtained by laser Doppler anemometry mixed with phase analysis light scattering (M3-PALS), measuring the mean electrophoretic mobility using a Zetasizer Nano ZS (Malvern, UK). For that, the samples were diluted with a millimolar solution of $\mathrm{NaCl}(1: 500)$.

Table I. Properties of Achyrocline satureioides Extract (mean $\pm \mathrm{SD})$

\begin{tabular}{lc}
\hline Property & Extract \\
\hline $\mathrm{pH}$ & $5.36 \pm 0.02$ \\
Density $(\mathrm{g} / \mathrm{mL})$ & $0.87 \pm 0.02$ \\
Dry residue $(w / w \%)$ & $1.44 \pm 0.01$ \\
Amount of quercetin $(\mu \mathrm{g} / \mathrm{mL})$ & $413.37 \pm 13.14$ \\
\hline
\end{tabular}




\section{Determination of Viscosity}

Viscosity of the nanoemulsion was evaluated in an Ostwald viscometer. Five milliliters of each nanoemulsion was poured into the filling tube and transferred to the capillary tube (viscometer constant; $k=0.0212$ ) by gentle suction. The time was recorded, in seconds, for the liquid to flow from the upper limit to the mark in the capillary tube.

\section{Determination of Quercetin Associated to Nanoemulsions}

For the determination of total quercetin in the formulation, $1 \mathrm{~mL}$ of nanoemulsion (NEQ or NEE) was appropriately diluted in methanol, filtered $(0.22-\mu \mathrm{m}$ PVDF membrane, Millipore, Brazil), and analyzed by HPLC.

For the association efficiency, free quercetin was determined in ultrafiltrate obtained by centrifugation using Amicon Ultra-4 (MWCO $10 \mathrm{kDa}$, Millipore, Brazil) at 5000g during $30 \mathrm{~min}$ at $4^{\circ} \mathrm{C}$ (2K15 centrifuge, Sigma Laborzentrifugen, Germany). The association efficiency (AE) was estimated by the difference between the total and free drug concentrations and expressed in percentage of total quercetin.

\section{In Vitro Percutaneous Permeation Study}

For the skin permeation studies, Franz diffusion cells with $2.54 \mathrm{~cm}^{2}$ and $10 \mathrm{~mL}$ of volume in the acceptor phase were employed. Porcine skin from the back part of the ear was used. Our previous experience shows that the thickness of skin (and stratum corneum) has a direct influence in the variability of the results. For that, skins with thickness of 0.9 $\pm 0.1 \mathrm{~mm}$ were used and the stratum corneum was removed by tape stripping (30 strippings; Scotch 750 tape, 3M, Brazil). The skin was hydrated with phosphate buffer saline (PBS $20 \mathrm{mM}$, $\mathrm{pH}$ 7.4). After that, the buffer was replaced by a $50 \%$ ethanol solution under magnetic stirring in a warm bath at $37^{\circ} \mathrm{C}$. Previous studies of quercetin solubility showed that $50 \%$ ethanol solution was the only acceptor phase that could guarantee sink conditions (18). In the donor phase, $1 \mathrm{~mL}$ of both NEQ and NEE was placed totalizing $100 \mu \mathrm{g}$ of quercetin. The concentration of quercetin in the acceptor phase was measured $8 \mathrm{~h}$ after nanoemulsion application. The samples were analyzed by HPLC and the data expressed as the amount of quercetin per area $\left(\mu \mathrm{g} / \mathrm{cm}^{2}\right)$. For the quantification of the remaining quercetin on the skin, the skin samples were washed with ethanol 50\%, weighed, and homogenized in a potter as well as in an ultrasound bath $(20 \mathrm{~min})$ to ensure the quercetin extraction from the skin. After quantification by HPLC, the results were expressed in micrograms of quercetin per gram of skin $(\mu \mathrm{g} / \mathrm{g})$.

\section{Antioxidant Activity of Nanoemulsions}

In order to assess the antioxidant activity of the formulation, thiobarbituric acid-reactive species (TBA-RS) assay was employed (28). The system chosen to cause oxidative damage was AAPH in egg yolk liposome (29), and the capacity of NEE and NEQ to avoid such damage, using NEB as a control, was evaluated. In a tube, $100 \mu \mathrm{L}$ of sample nanoemulsion, diluted three times (quercetin solution or extract at the same quercetin concentration for the controls), $1000 \mu \mathrm{L}$ of $1 \%$ egg yolk, and $100 \mu \mathrm{L}$ of AAPH were added and reacted for $30 \mathrm{~min}$ at $37^{\circ} \mathrm{C}$ in order to induce oxidative stress. A $300-\mu \mathrm{L}$ aliquot of the supernatant was mixed with $600 \mu \mathrm{L}$ of a thiobarbituric acid solution, heated in a boiling bath for $30 \mathrm{~min}$, and then read using a spectrophotometer at $532 \mathrm{~nm}$. A curve of TMP was used as a standard. Also, the in vitro protection level offered by the formulations against lipoperoxidation in porcine skin was analyzed. A TBA-RS assay was performed on the skin that was submitted to the permeation process, using nontreated skin as a control. This assay can help to understand the effect of the formulation, if any, in order to inhibit the damage to lipids present in the tissue. For that, the tissues $\left(2.54 \mathrm{~cm}^{2}\right.$ of skin-around $\left.300 \mathrm{mg}\right)$ were trimmed and manually homogenized in a PBS buffer in a glass homogenizer. After that, $600 \mu \mathrm{L}$ of $15 \%$ trichloroacetic acid was added to $300 \mu \mathrm{L}$ of sample and centrifuged (11,000 rpm, $10 \mathrm{~min}$ ). A 300$\mu \mathrm{L}$ aliquot of the supernatant was mixed with $600 \mu \mathrm{L}$ of a thiobarbituric acid solution, heated in a boiling bath for $30 \mathrm{~min}$, and then read using a spectrophotometer at $532 \mathrm{~nm}$. A curve of TMP was employed as a standard. The proteins were quantified according to the method proposed by Lowy et al. (1956) (30).

\section{Statistical Analysis}

The results were expressed as mean \pm standard deviation (SD) of three independent experiments. Statistical analysis was performed by ANOVA, followed by Tukey's test $(p<0.05)$.

\section{RESULTS}

\section{Preparation and Characterization of Nanoemulsions}

In the early development, the physicochemical properties of NEE showed to be especially sensitive to the amount of extract incorporated, expressed in terms of dry residue. Increasing size and polydispersity of the droplets followed the increase of dry residue, as observed in Fig. 1. The standard deviation, which can be related to reproducibility, also increased with the dry residue amount. For this reason, a final concentration of quercetin of $100 \mu \mathrm{g} / \mathrm{mL}$ and a final dry residue of $0.30 \%$ using $2.419 \mathrm{~mL}$ of extract (third column) were chosen. A more complete data set of this formulation can be observed in Table II. As a means of comparison, NEQ and NEB were also prepared. The formulations proved to be monodisperse $(\mathrm{PDI}<0.2)$ with an average size between 170 and $300 \mathrm{~nm}$. However, a significant increase in the size of NEE $(p<0.05)$ could be observed in comparison to NEB and NEQ. The zeta potential was also higher (in modulus) for NEE $(-43.6 \mathrm{mV})$ than for blank or quercetin-loaded nanoemulsion (-24.8 and $-27.4 \mathrm{mV}$, respectively). Viscosity did not change regardless of the formulation. Only traces of quercetin could be detected in the ultrafiltrate, but this was below the quantification limit of the method $(0.044 \mu \mathrm{g} / \mathrm{mL})$, suggesting association efficiency to be nearly $100 \%$ for quercetin. This high affinity of the nanoemulsion for lipophilic compounds such as quercetin can be better visualized in Fig. 2. Furthermore, qualitative analysis indicated that other compounds that have been described for this extractive solution of $A$. satureioides had important association to this nanoemulsion (not 


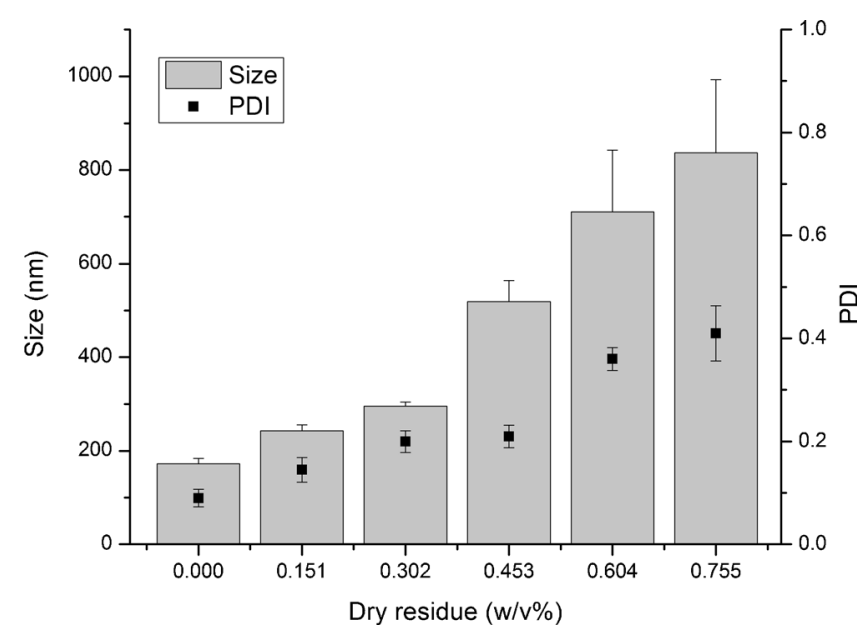

Fig. 1. Influence of the amount of dry residue incorporated in the average size of the nanoemulsions

quantified), such as 3-O-methylquercetin, luteolin, and the chalcone achyrobichalcone. The total amount of quercetin detected for the formulation was $102.5 \pm 4.7$ and $101.3 \pm 0.8 \mu \mathrm{g} /$ $\mathrm{mL}$ for NEQ and NEE, respectively. No statistical difference between the final concentrations of quercetin in both formulations could be observed $(p<0.05)$.

\section{In Vitro Percutaneous Permeation of Quercetin}

As shown in Table III, the permeation profile of quercetin appears to be affected by the manner the flavonoid was incorporated within the nanostructures (isolated or in extract). No quercetin from NEQ could be detected in the acceptor phase after $8 \mathrm{~h}$ of study. The level of quercetin retained in the skin is approximately 2.5 times higher for NEE $(16.2 \mu \mathrm{g} / \mathrm{g})$, as compared to that for NEQ $(6.3 \mu \mathrm{g} / \mathrm{g})$.

\section{Antioxidant Activity}

First, an in vitro antioxidant study was performed in order to understand the influence of nanoencapsulation in the antioxidant profile and protection offered by the formulations against lipoperoxidation induced by AAPH. The effect of encapsulation of quercetin (isolated or in extract) in the antioxidant profile against AAPH oxidative damage is shown in Fig. 3a. The data indicate protection against lipoperoxidation in the order of $8.3 \%$ for quercetin solution and $72.6 \%$ for quercetin in nanoemulsion (NEQ). A similar effect was observed for nanoemulsions containing extract (NEE) when compared to the extract alone; an inhibition of $77.6 \%$ (NEE) and $43.3 \%$ (extract) was observed. The lipoperoxidation

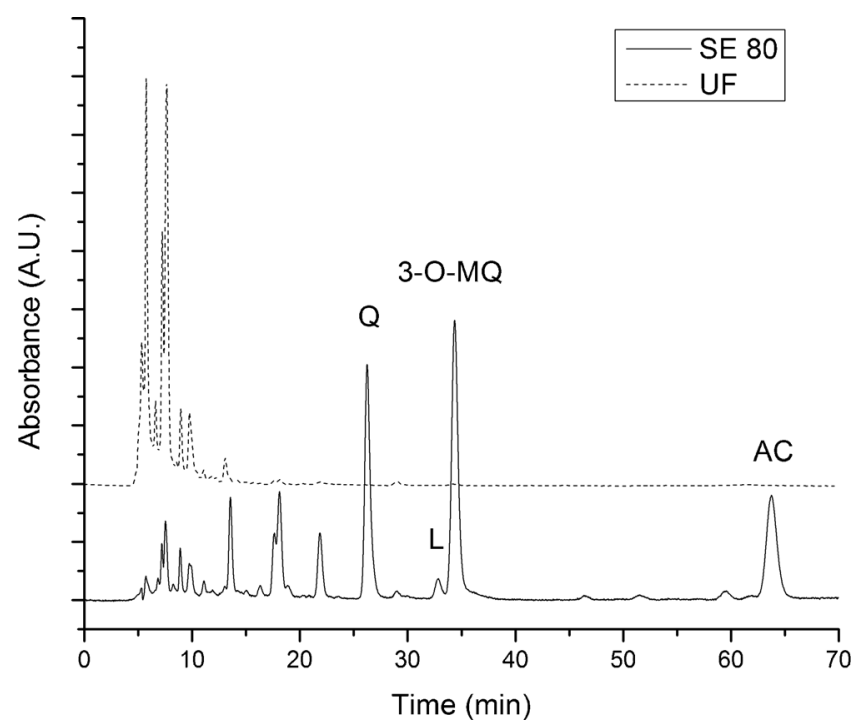

Fig. 2. Chromatogram of extract (full line; 50× diluted) and ultrafiltrated NEE (dotted line). It can be seen that important flavonoids (quercetin $(Q)$, luteolin $(L), 3$-O-methylquercetin and achyrobichalcone $(A C)$ ) were completely incorporated to the nanoemulsion structure in the assayed conditions

found after treatment with NEQ and NEE (27.4 and 22.4\%, respectively) was inferior to the $107.8 \%$ found for NEB (Fig. 3b). No difference between the antioxidant effect of NEQ and NEE $(p<0.05)$ could be observed. Finally, the production of TBA-RS in the skin after the permeation process was quantified (Fig. 4). A reduction in the production of TBARS in the skin treated with NEE could be observed when compared with both NEB and NEQ treatments.

\section{DISCUSSION}

\section{Preparation and Characterization of Nanoemulsions}

The use of a vegetal extract instead of an isolated active substance is interesting once many compounds in the extract act in a synergistic way, thus having their activity increased (31). Due to the poor water solubility of flavonoids, we developed nanoemulsions to associate quercetin either isolated or in A. satureioides extract.

The physicochemical properties of the nanoemulsions are in accordance to formulations with similar composition obtained by spontaneous emulsification $(18,22,32)$. However, some properties presented by the NEE were different than those for NEB and NEQ. When the extract was incorporated to the nanoemulsion, the average size was remarkably higher.

Table II. Physicochemical Properties of Nanoemulsions

\begin{tabular}{lllllll}
\hline Formulation & Size $(\mathrm{nm})$ & PDI & $\zeta$ potential $(\mathrm{mV})$ & Viscosity $(\mathrm{cP})$ & $\begin{array}{c}\text { Quercetin content } \\
(\mu \mathrm{g} / \mathrm{mL})\end{array}$ & $\begin{array}{c}\text { Association } \\
\text { efficiency }(\%)\end{array}$ \\
\hline NEB & $172.5 \pm 6.6$ & $0.098 \pm 0.017$ & $-24.8 \pm 2.3$ & $1.57 \pm 0.01$ & - & - \\
NEQ & $197.0 \pm 10$ & $0.241 \pm 0.022$ & $-27.4 \pm 6.0$ & $1.62 \pm 0.02$ & $102.5 \pm 4.7$ & $>99^{a}$ \\
NEE & $295.6 \pm 9.0$ & $0.211 \pm 0.021$ & $-43.6 \pm 2.1$ & $1.65 \pm 0.01$ & $101.3 \pm 0.8$ & $>99^{a}$ \\
\hline
\end{tabular}

$N E B$ blank nanoemulsion, $N E Q$ quercetin-loaded nanoemulsion, $N E E$ extract-loaded nanoemulsion

${ }^{a}$ Lower than the limit of quantification $(0.044 \mu \mathrm{g} / \mathrm{mL})$ 
Table III. Amount of Permeated and Retained Quercetin in Skin After an 8-h Permeation

\begin{tabular}{lll}
\hline & \multicolumn{2}{l}{ Quercetin amount } \\
\cline { 2 - 3 } & Permeated $\left(\mu \mathrm{g} / \mathrm{cm}^{2}\right)$ & Retained $(\mu \mathrm{g} / \mathrm{g})$ \\
\hline $\mathrm{NEQ}$ & $\mathrm{ND}$ & $6.28 \pm 1.23$ \\
$\mathrm{NEE}$ & $1.29 \pm 0.19$ & $16.23 \pm 2.56$ \\
\hline
\end{tabular}

$N E Q$ quercetin-loaded nanoemulsion, $N E E$ extract-loaded nanoemulsion, $N D$ not detected

Interactions between phospholipids and flavonoids have been described in prior literature (33-35); however, they solely cannot explain this behavior once NEQ had similar properties to NEB. In addition, some compounds present in the extract
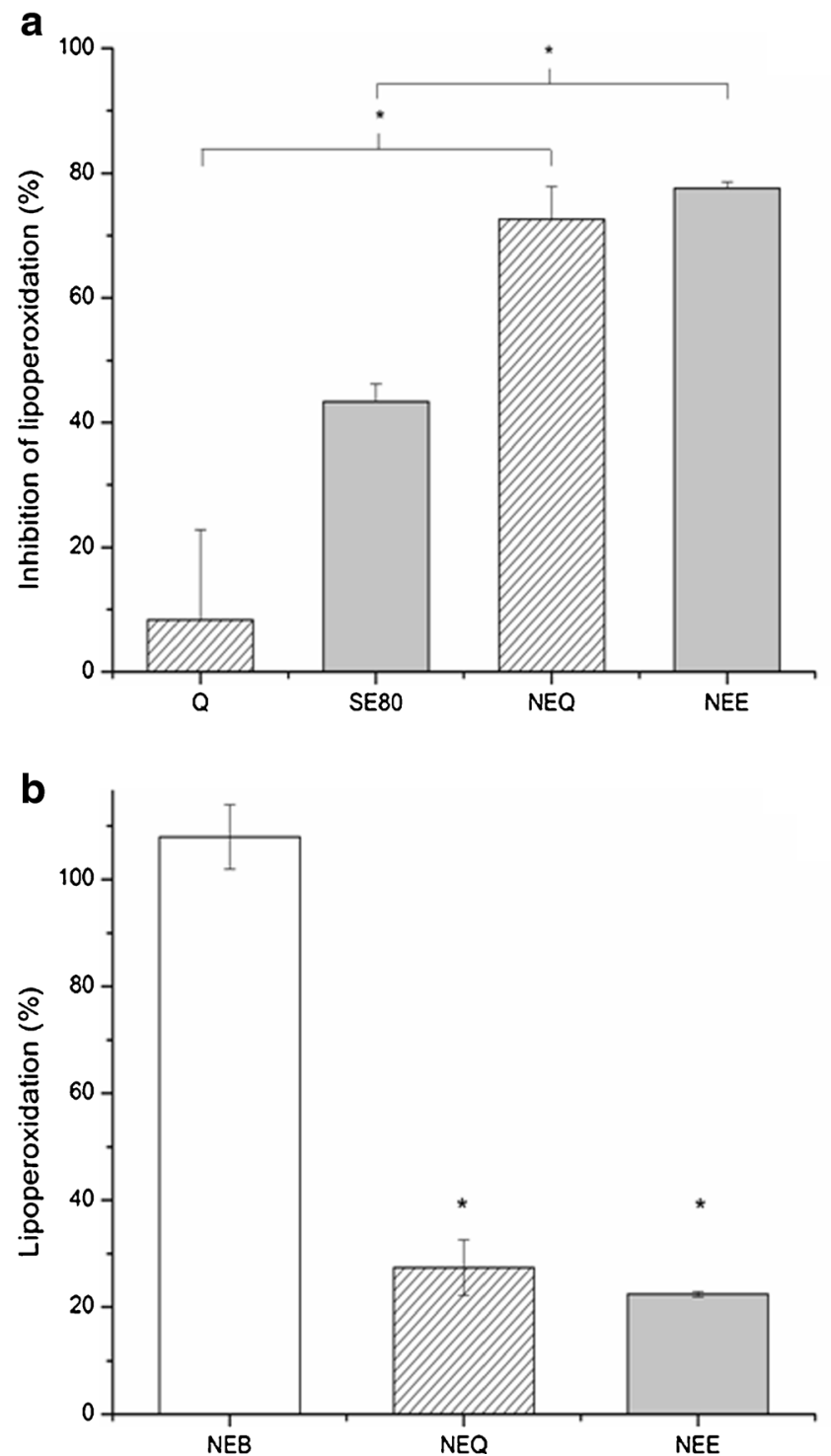

Fig. 3. Antioxidant study: a influence of nanoencapsulation on the antioxidant profile and $\mathbf{b}$ percentage of lipoperoxidation induced by AAPH. $Q$ quercetin, SE80 Achyrocline satureioides extract, $N E Q$ quercetin-loaded nanoemulsion, $N E E$ extract-loaded nanoemulsion. Asterisk denotes difference in respect of control and number sign indicates difference between treatment; $p<0.05$

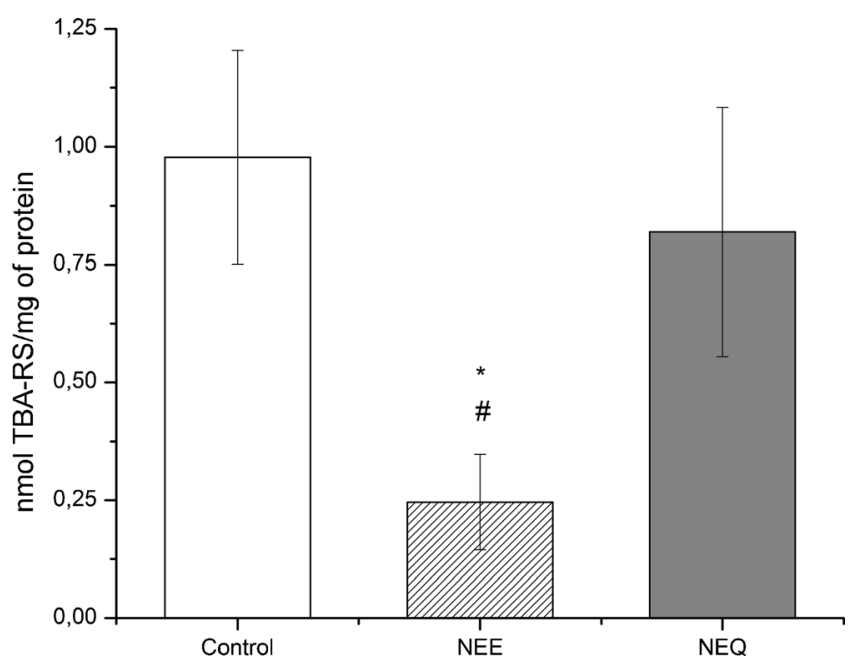

Fig. 4. TBA-RS production in porcine skin. Control non-treated skin, $N E Q$ quercetin-loaded nanoemulsion, and $N E E$ extract-loaded nanoemulsion. Asterisk indicates difference in respect of control and number sign represents difference between treatment; $p<0.05$

could decrease the velocity of solvent diffusion. The diffusion velocity of organic phases in water is one of the major parameters that affect the diameter of nanostructures obtained by solvent displacement (36). Finally, the adsorption of some constituents of the extract onto the nanoemulsion surface may well have increased the hydrodynamic radius. This adsorption phenomenon in the nanoemulsion interface could also be responsible for the significant decrease in the NEE zeta potential in comparison to NEQ. For the NEQ, the results obtained contradict Fasolo et al. (2009), who described a significant reduction in the zeta potential of quercetinloaded nanoemulsions (18). However, such difference can be attributed to the 10-times higher concentration of quercetin ( $1 \mathrm{mg} / \mathrm{mL})$ used by these authors. The results found for the NEE are in line with those reported by Bidone et al. (2014) who studied nanoemulsions with similar extracts for 3-Omethylquercetin association (22). Concerning the high association efficiency found, this may be attributed to greater affinity of quercetin to the nanoemulsion internal phase (37). Interestingly, other compounds with poor solubility such as the chalcone achyrobichalcone and the flavonoids 3-Omethylquercetin and luteolin may find in nanoemulsified systems as one way to improve their biopharmaceutical properties $(9,38,39)$. Finally, there are reports in the literature of higher viscosity for systems with lower mean sizes, with these phenomena attributed to an increase of interparticular interactions (37). However, in this study, this does not seem to be the case. The viscosity of Newtonian fluids, such as nanoemulsions, only appears to change in higher concentrations of the internal phase $(21,40)$.

\section{In Vitro Percutaneous Permeation of Quercetin}

The choice of the skin permeation model was based on the fact that pig epidermis can be histologically compared to human skin in terms of thickness and cellular structures and that the information obtained could be related to a human skin behavior (41). The evaluation of the permeation of polyphenolic compounds, using porcine skin with Franz diffusion 
cells, has been widely performed (42-44). The results obtained in this study for quercetin (NEQ) are lower than those previously reported (13). The difference may be due to the lower concentration (10-fold) employed in the present work that could interfere with the quercetin diffusion in the skin. However, quercetin could be detected in the acceptor phase from NEE $\left(\sim 1.3 \mu \mathrm{g} / \mathrm{cm}^{2}\right)$, indicating that some extract compounds may well have an influence in its permeation capacity. The low permeation observed could be due to quercetin retention in the skin. For this reason, the determination of remaining quercetin in the skin was carried out, showing higher retention of quercetin for NEE in comparison to NEQ (2.5-fold higher). The reason for this fact is yet to be understood. Some extract compounds could have some influence on the epidermis or dermis, thus contributing to the quercetin permeation, or even contribute to lowering of the interaction between the flavonoid and the nanostructure, thus favoring its release (45). Nevertheless, more studies are required to fully characterize this behavior. It is important to highlight that these results reflect the use of skin that had their stratum corneum partially removed. This means that the results observed overestimate the permeation of quercetin in intact skin. In many clinical conditions, the integrity of the stratum corneum is compromised and its removal is part of some in vitro protocols (46). For example, herpes infection by HSV-1 is known to damage both the skin and oral mucosa. The antiviral activity of A. satureioides ethanolic extract was already described (47), and recently, a nanoemulsion associating this extract was proposed for topical treatment of herpes (22).

\section{Antioxidant Activity}

TBA-RS was performed to assay the antioxidant capacity of the formulation based on the ability to detect lipoperoxidation products. The most important substance of lipid degradation is malondialdehyde, which reacts with thiobarbituric acid, giving rise to a colored product that can be read in a spectrophotometer. The antioxidant activity was evaluated using a model to induce oxidative stress consisting of AAPH and egg yolk. The antioxidant activity of the ethanolic extract (SE80) was higher than the isolated quercetin (Q). It is known that some fractions of $A$. satureioides extracts can exhibit synergism, as compared to a solution of pure quercetin, thus increasing their antioxidant properties (8). The increase of antioxidant effect after nanoencapsulation has been previously reported by some authors. The natural compounds curcumin and resveratrol, as well as grape extract, are among those which had their activity improved after association to lipid-based nanostructures $(48,49)$. The explanation may rely on the kinetic release of the antioxidants from the oil core. 3-O-Methylquercetin is known to have a first-order release kinetics from nanoemulsions, similarly as the oxidation rates observed for curcumin- and resveratrol-loaded nanocapsules $(22,48)$. However, when associated to the nanoemulsions, the antioxidant effect of both quercetin and the extract increased significantly until no difference could be found between NEQ and NEE. These data suggest that the effect of the other $A$. satureioides extract compounds (which exist when the SE80 is used) is minimized when encapsulated.

Finally, the in vitro measurement of nanoemulsion antioxidant activity, carried out against lipoperoxidation in porcine skin, showed that the NEE had significant activity when compared to the NEB or NEQ. The explanation of this phenomena cannot be the synergistic effect of the extract compounds once no difference was observed in the in vitro activity of NEQ and NEE in the egg yolk model. However, this reduction may well be attributed to the higher amount of quercetin retained in the skin treated with NEE. A minimal amount of quercetin in the skin $(16.2 \mu \mathrm{g} / \mathrm{g})$ was enough to produce an antioxidant effect, showing the feasibility of the use of nanoemulsions containing $A$. satureioides extract.

\section{CONCLUSIONS}

The data presented reveal the influence of the nanoemulsion composition in the physicochemical properties as well as in the permeation profile and antioxidant activity. The use of nanoemulsions could increase the intrinsic antioxidant activity of quercetin and the extract. Formulations containing A. satureioides extractive solution proved to be more effective than the isolated quercetin to avoid lipoperoxidation in the skin. The higher activity is attributed to the higher retention of quercetin in the skin, probably due the presence of other unknown compounds in the extract. These data sets suggest a promissory future for the use of $A$. satureioides extract rather than isolated quercetin for topical nanoemulsions.

\section{ACKNOWLEDGMENTS}

The authors want to thank CAPES and CNPq for the financial support. The authors also thank Dr. SS Guterres and Dr. PR Petrovick for allowing the use of their facilities.

\section{REFERENCES}

1. Pinnell SR. Cutaneous photodamage, oxidative stress, and topical antioxidant protection. J Am Acad Dermatol. 2003;48(1):1-22. doi:10.1067/mjd.2003.16.

2. Ratnam DV, Ankola DD, Bhardwaj V, Sahana DK, Kumar MNVR. Role of antioxidants in prophylaxis and therapy: a pharmaceutical perspective. J Control Release. 2006;113(3):189-207. doi:10.1016/j.jconrel.2006.04.015.

3. Halliwell B. Role of free radicals in the neurodegenerative diseases. Drugs Aging. 2001;18(9):685-716.

4. Halliwell B, Gutteridge JMC. Free radicals in biology and medicine. 4th ed. Oxford: Oxford University Press; 2007.

5. Simões CMO, Schenkel EP, Bauer L, Langeloh A. Pharmacological investigations on Achyrocline satureioides (Lam.) DC., compositae. J Ethnopharmacol. 1988;22(3):281-93. doi:10.1016/ 0378-8741(88)90239-5.

6. Retta D, Dellacassa E, Villamil J, Suárez SA, Bandoni AL. Marcela, a promising medicinal and aromatic plant from Latin America: a review. Ind Crop Prod. 2012;38:27-38. doi:10.1016/ j.indcrop.2012.01.006.

7. Stolz ED, Müller LG, Trojan-Rodrigues M, Baumhardt E, Ritter MR, Rates SMK. Survey of plants popularly used for pain relief in Rio Grande do Sul, southern Brazil. Rev Brasileira Farmacogno. 2014;24(2):185-96. doi:10.1016/j.bjp.2014.03.007.

8. Desmarchelier C, Coussio J, Ciccia G. Antioxidant end free radical scavenging effects of the medicinal herb Achyrocline satureioides (Lam.) DC. ("marcela"). Braz J Med Biol Res. 1998;31:1163-70.

9. De Souza KCB, Schapoval EES, Bassani VL. LC determination of flavonoids: separation of quercetin, luteolin and 3-O-methylquercetin in Achyrocline satureioides preparations. J Pharm Biomed Anal. 2002;28(3-4):771-7. doi:10.1016/S0731-7085(01)00693-8. 
10. Polydoro M, de Souza KCB, Andrades ME, Da Silva EG, Bonatto $\mathrm{F}$, Heydrich $\mathrm{J}$, et al. Antioxidant, a pro-oxidant and cytotoxic effects of Achyrocline satureioides extracts. Life Sci. 2004;74(23):2815-26. doi:10.1016/j.lfs.2003.09.073.

11. Cao G, Sofic E, Prior RL. Antioxidant and prooxidant behavior of flavonoids: structure-activity relationships. Free Radic Biol Med. 1997;22(5):749-60. doi:10.1016/S0891-5849(96)00351-6.

12. Casagrande R, Georgetti SR, Verri Jr WA, Borin MF, Lopez RFV, Fonseca MJV. In vitro evaluation of quercetin cutaneous absorption from topical formulations and its functional stability by antioxidant activity. Int J Pharm. 2007;328(2):183-90. doi:10.1016/j.ijpharm.2006.08.006.

13. Casagrande R, Georgetti SR, Verri Jr WA, Dorta DJ, dos Santos AC, Fonseca MJV. Protective effect of topical formulations containing quercetin against UVB-induced oxidative stress in hairless mice. J Photochem Photobiol B Biol. 2006;84(1):21-7. doi:10.1016/j.jphotobiol.2006.01.006.

14. Benita S. Prevention of topical and ocular oxidative stress by positively charged submicron emulsion. Biomed Pharmacotherap. 1999;53(4):193-206. doi:10.1016/S07533322(99)80088-2.

15. Gutiérrez JM, González C, Maestro A, Solè I, Pey CM, Nolla J. Nano-emulsions: new applications and optimization of their preparation. Curr Opin Colloid Interface Sci. 2008;13(4):245-51. doi:10.1016/j.cocis.2008.01.005.

16. Srinivas K, King JW, Howard LR, Monrad JK. Solubility and solution thermodynamic properties of quercetin and quercetin dihydrate in subcritical water. J Food Eng. 2010;100(2):208-18. doi:10.1016/j.jfoodeng.2010.04.001.

17. Razmara RS, Daneshfar A, Sahraei R. Solubility of quercetin in water + methanol and water + ethanol from (292.8 to 333.8) K. J Chem Eng Data. 2010;55(9):3934-6. doi:10.1021/je9010757.

18. Fasolo D, Bassani VL, Teixeira HF. Development of topical nanoemulsions containing quercetin and 3-O-methylquercetin. Die Pharmazie - Int J Pharmaceut Sci. 2009;64(11):726-30. doi:10.1691/ph.2009.8357.

19. Silva AP, Nunes BR, De Oliveira MC, Koester LS, Mayorga P, Bassani VL, et al. Development of topical nanoemulsions containing the isoflavone genistein. Pharmazie. 2009;64(1):32-5.

20. Solans C, Izquierdo P, Nolla J, Azemar N, Garcia-Celma MJ. Nanoemulsions. Curr Opin Colloid Interface Sci. 2005;10(3-4):102-10. doi:10.1016/j.cocis.2005.06.004.

21. Tadros T, Izquierdo P, Esquena J, Solans C. Formation and stability of nano-emulsions. Adv Colloid Interf Sci. 2004;108109:303-18.

22. Bidone J, Zorzi GK, Carvalho ELS, Simões CMO, Koester LS, Bassani VL, et al. Incorporation of Achyrocline satureioides (Lam.) DC extracts into topical nanoemulsions obtained by means of spontaneous emulsification procedure. Ind Crop Prod. 2014;62:421-9. doi:10.1016/j.indcrop.2014.08.042.

23. Sahoo SK, Parveen S, Panda JJ. The present and future of nanotechnology in human health care. Nanomed: Nanotechnol, Biol, Med. 2007;3:20-31.

24. Sarker DK. Engineering of nanoemulsions for drug delivery. Curr Drug Deliv. 2005;2(4):297-310.

25. Deutsches Arzneibuch. 9. Ausgabe. . Stuttgart:Wissenschaftliche; 1986.

26. Convention USP. United States Pharmacopeia and National Formulary (USP 36-NF 31). Rockville2013.

27. Carvalho ELS, Poser GL, Zorzi GK, Teixeira HF, Moreira JCF, Bassani VL. Nanoestrutura compreendendo extratos vegetais, processo de produção de nanoestrutura compreendendo extratos vegetais e composições compreendendo as mesmas. Brazil: Universidade Federal do Rio Grande do Sul; 2008.

28. Esterbauer H, Cheeseman KH. Determination of aldehydic lipid peroxidation products: malonaldehyde and 4-hydroxynonenal. In: Lester Packer ANG, editor. Methods in enzymology: Academic Press; 1990. p. 407-21.

29. Melo MGD, dos Santos JPA, Serafini MR, Caregnato FF, de Bittencourt Pasquali MA, Rabelo TK, et al. Redox properties and cytoprotective actions of atranorin, a lichen secondary metabolite. Toxicol in Vitro. 2011;25(2):462-8. doi:10.1016/j.tiv.2010.11.014.

30. Lowry OH, Rosebrough NJ, Farr AL, Randall RJ. Protein measurement with the folin phenol reagent. J Biol Chem. 1951;193(1):265-75.
31. Wagner H, Ulrich-Merzenich G. Synergy research: approaching a new generation of phytopharmaceuticals. Phytomedicine. 2009;16(2-3):97-110. doi:10.1016/j.phymed.2008.12.018.

32. de Vargas BA, Bidone J, Oliveira LK, Koester LS, Bassani VL, Teixeira HF. Development of topical hydrogels containing genistein-loaded nanoemulsions. J Biomed Nanotechnol. 2012;8(2):330-6. doi:10.1166/jbn.2012.1386.

33. Ollila F, Halling K, Vuorela P, Vuorela H, Slotte JP. Characterization of flavonoid-biomembrane interactions. Arch Biochem Biophys. 2002;399(1):103-8. doi:10.1006/abbi.2001.2759.

34. Saija A, Scalese M, Lanza M, Marzullo D, Bonina F, Castelli F. Flavonoids as antioxidant agents: importance of their interaction with biomembranes. Free Radic Biol Med. 1995;19(4):481-6. doi:10.1016/0891-5849(94)00240-K.

35. Tammela P, Laitinen L, Galkin A, Wennberg T, Heczko R, Vuorela $\mathrm{H}$, et al. Permeability characteristics and membrane affinity of flavonoids and alkyl gallates in Caco-2 cells and in phospholipid vesicles. Arch Biochem Biophys. 2004;425(2):1939. doi:10.1016/j.abb.2004.03.023.

36. Bouchemal K, Briançon S, Perrier E, Fessi H. Nano-emulsion formulation using spontaneous emulsification: solvent, oil and surfactant optimisation. Int J Pharm. 2004;280(1-2):241-51. doi:10.1016/j.ijpharm.2004.05.016.

37. Ishii F, Sasaki I, Ogata H. Effect of phospholipid emulsifiers on physicochemical properties of intravenous fat emulsions and/or drug carrier emulsions. J Pharm Pharmacol. 1990;42:513-5.

38. Holzschuh MH, Gosmann G, Schneider PH, Schapoval EES, Bassani VL. Identification and stability of a new bichalcone in Achyrocline satureioides spray dried powder. Die Pharmazie - Int J Pharmaceut Sci. 2010;65(9):650-6. doi:10.1691/ph.2010.0085.

39. Lopez-Lazaro M. Distribution and biological activities of the flavonoid luteolin. Mini-Rev Med Chem. 2009;9(1):31-59. See more at: http://www.eurekaselect.com/83639/article\#sthash.IS3boy82.dpuf.

40. Silvander M, Hellström A, Wärnheim T, Claesson P. Rheological properties of phospholipid-stabilized parenteral oil-in-water emulsions-effects of electrolyte concentration and presence of heparin. Int J Pharm. 2003;252(1-2):123-32. doi:10.1016/S03785173(02)00626-9.

41. Fernandez C, Marti-Mestres G, Ramos J, Maillols H. LC analysis of benzophenone-3: II application to determination of 'in vitro' and 'in vivo' skin penetration from solvents, coarse and submicron emulsions. J Pharm Biomed Anal. 2000;24(1):155-65. doi:10.1016/S0731-7085(00)00399-X.

42. Intarakumhaeng R, Li SK. Effects of solvent on percutaneous absorption of nonvolatile lipophilic solute. Int J Pharm. 2014;476(1-2):266-76. doi:10.1016/j.ijpharm.2014.09.034.

43. Thitilertdecha P, Rowan MG, Guy RH. Topical formulation and dermal delivery of active phenolic compounds in the Thai medicinal plant-Clerodendrum petasites S. Moore. Int J Pharm. 2015;478(1):39-45. doi:10.1016/j.ijpharm.2014.11.004.

44. Yamashita F, Hashida M. Mechanistic and empirical modeling of skin permeation of drugs. Adv Drug Deliv Rev. 2003;55(9):118599. doi:10.1016/S0169-409X(03)00118-2.

45. Ajazuddin SS. Applications of novel drug delivery system for herbal formulations. Fitoterapia. 2010;81(7):680-9. doi:10.1016/ j.fitote.2010.05.001.

46. Saija A, Tomaino A, Trombetta D, Giacchi M, De Pasquale A, Bonina F. Influence of different penetration enhancers on in vitro skin permeation and in vivo photoprotective effect of flavonoids. Int J Pharm. 1998;175(1):85-94. doi:10.1016/S03785173(98)00259-2.

47. Bettega JM, Teixeira H, Bassani VL, Barardi CR, Simoes CM. Evaluation of the antiherpetic activity of standardized extracts of Achyrocline satureioides. Phytother Res : PTR. 2004;18(10):81923. doi:10.1002/ptr.1568.

48. Coradini K, Lima FO, Oliveira CM, Chaves PS, Athayde ML, Carvalho LM, et al. Co-encapsulation of resveratrol and curcumin in lipid-core nanocapsules improves their in vitro antioxidant effects. Eur J Pharm Biopharm. 2014;88(1):178-85. doi:10.1016/ j.ejpb.2014.04.009.

49. Spigno G, Donsì F, Amendola D, Sessa M, Ferrari G, De Faveri DM. Nanoencapsulation systems to improve solubility and antioxidant efficiency of a grape marc extract into hazelnut paste. J Food Eng. 2013;114(2):207-14. doi:10.1016/ j.jfoodeng.2012.08.014. 